\title{
A Review of Clinical Translation of Inorganic Nanoparticles
}

\author{
Aaron C. Anselmo ${ }^{1}$ and Samir Mitragotri ${ }^{1,2}$
}

Received 4 March 2015; accepted 28 April 2015; published online 9 May 2015

\begin{abstract}
Inorganic nanoparticles are widely used for therapeutic and diagnostic purposes as they offer unique features as compared with their organic and polymeric counterparts. As such, inorganic nanoparticles represent an exciting opportunity to develop drug delivery and imaging systems that are poised to tackle unique challenges which are currently unaddressed in clinical settings. Despite these clear advantages, very few inorganic nanoparticle systems have entered the clinic. Here, we review the current clinical landscape of inorganic nanoparticle systems and their opportunities and challenges, with particular emphasis on gold-, iron-oxide- and silica-based nanoparticle systems. Key examples of inorganic nanoparticles that are currently being investigated in the clinic (e.g., trials which are recruiting or currently active but not completed) are highlighted, along with the preclinical work that these examples have leveraged to transition from the lab to the clinic.
\end{abstract}

KEY WORDS: clinical translation; clinical trials; drug delivery; drug delivery systems; gold; inorganic nanoparticles; iron oxide; metals; nanoparticles; silica.

\section{INTRODUCTION}

Inorganic nanoparticles, including gold, iron oxide, silver, or silica, among others, are investigated in both preclinical and clinical studies for the treatment, diagnosis, and detection of many diseases (1-5). Additionally, many of the inorganic compounds that serve as the material for making nanoparticles have long been used in the clinic for various therapeutic applications (6,7). Prominent examples of inorganic compounds used for therapeutic applications include platinum (e.g., cisplatin, carboplatin, oxaliplatin, etc.) for the treatment of cancer (6) and silver ions as antibacterial agents (8). However, there is a severe lack of both clinically investigated and clinically approved inorganic "nanoparticle" products $(9,10)$, despite the clinical use of inorganic drugs and materials in general.

As is the case with their organic therapeutic counterparts, inorganic therapeutics can benefit from being formulated as a nanoparticle delivery system to improve their biological performance by enhancing pathological targeting, drug loading, and immune system evasion $(11,12)$. Additional functions (e.g., thermal heating) can be performed for certain inorganic particles, for example, gold nanoparticles, which leverage the use of their surface plasmon resonance (13). Furthermore, certain inorganic nanoparticles can respond to specific external stimuli such as magnetic fields or near-

\footnotetext{
${ }^{1}$ Department of Chemical Engineering, Center for Bioengineering, University of California, Santa Barbara, California 93106, USA.

${ }^{2}$ To whom correspondence should be addressed. (e-mail: samir@engineering.ucsb.edu)
}

infrared (NIR) light to enhance magnetic imaging (2) or facilitate on-demand drug release (14), respectively. Additionally, many inorganic nanoparticles can be synthesized and tuned in a way that facilitates incorporation of ligands or polymers to further enhance their biological function (15).

This review will focus on the clinical translation of inorganic nanoparticles, with special emphasis on key clinical trials that are currently recruiting or ongoing (e.g., not completed) with gold, iron oxide, and silica nanoparticles. These nanoparticles are selected since they are the most widely investigated types of inorganic nanoparticles. In addition, special focus will be placed on the early preclinical work of these key clinical trials to highlight the path these nanoparticles have taken from the lab to the clinic. Furthermore, the challenges and opportunities faced in these currently ongoing clinical trials and the broad class of inorganic nanoparticles will be highlighted and discussed in depth. Detailed discussion on the preclinical success of inorganic nanoparticles for therapeutic or diagnostic applications is beyond the scope of this review article, as it has been extensively reviewed elsewhere $(1,3,16)$.

\section{GOLD NANOPARTICLES}

\section{Background and Successes in Preclinical Studies}

Noble metal (i.e., platinum, gold, and silver) nanoparticles distinguish themselves from other particle types, either organic or inorganic, by their unique surface plasmon resonance (SPR) which arises from their nanoparticle-sized photon confinement (17). Of these noble metal nanoparticles, gold nanoparticles are by far the most widely investigated, 
given their distinct advantages for drug delivery, diagnostic, and therapeutic applications $(4,17,18)$. Many unique therapeutic opportunities of AuNPs, for example, imaging, make use of their light-scattering properties. Other therapeutic opportunities, such as AuNP-mediated tumor ablation, arise from their photothermal properties, which stem from AuNP intrinsic abilities to absorb light. Optical and photothermal functions can be precisely controlled and tuned by changing parameters including size, shape, structure, and composition of AuNPs (17). As such, extensive research has been performed to elucidate the role of nanoparticle parameters in modulating the optical and photothermal properties of AuNPs (19). These modifications can be employed into AuNP design by using a variety of synthesis techniques (13). Other, more traditional therapeutic opportunities include loading of AuNPs with a variety of therapeutic molecules through surface modification. Therapeutics such as proteins (20), peptides (21), siRNA (22), and drugs (23) have been previously incorporated with AuNPs and used for preclinical in vitro or in vivo applications. Furthermore, the AuNPs SPR can be used to facilitate on-demand release of these therapeutics via externally triggering stimuli (e.g., light) (16). Additional benefits include the inertness of AuNPs which is evident from their limited toxicity to cells (24). For these reasons, AuNPs are extensively used and investigated at the preclinical stage and have been used in many therapeutic and diagnostic applications at a preclinical level. The preclinical successes of AuNPs are beyond the scope of this review article, and special focus will be made on efforts at the forefront of the clinical translation of AuNPs.

\section{Current Clinical Trials}

The history of colloidal gold being used to confer health benefits goes back centuries (25). The first proven successes of the health benefits of colloidal gold include its use as a source of radiation for brachytherapy (26) and for its use in the treatment of arthritis (27). These early successes have certainly increased interest in utilizing gold and other noble metals for healthcare applications. Some AuNPs such as Aurimune, a tumor necrosis factor-bound AuNP, have completed key clinical trials (NCT00356980 and NCT00436410 from www.clinicaltrials.gov) and are paving the way for many of the systems highlighted here. While no AuNP products have been clinically approved, a select few, all which leverage the light absorption properties of AuNPs, are being investigated for a variety of therapeutic applications ranging from treating solid tumors to treating acne. The first example, known as AuroLase $\AA$ and being developed by Nanospectra, are silica-gold nanoshells coated with (poly)ethylene glycol (PEG) designed to thermally ablate solid tumors following stimulation with a near-infrared energy source (28). The silica core serves as the dielectric core, the gold shell grants thermal ablation ability following the intense absorption of near-infrared NIR light, and the PEG layer provides overall particle stability (29). This technology was first reported over 10 years ago (29). The key findings of this seminal work, which set the foundation for AuroLase ${ }^{\circledR}$, showed that AuroLase $\AA$ could be used to: (i) induce photothermal cell death, in vitro, following stimulation with a NIR energy source (Fig. 1a (i, ii)) and (ii) increase solid tumor temperatures (Fig. 1b (i, ii)) to induce irreversible thermal damage to tumors (Fig. 1c (i-iv)) in mice following intratumoral injection (29). In a follow-up work, AuroLase ${ }^{\circledR}$ was used for thermal ablation treatment of brain (30) and prostate (31) cancers, with the latter showing the potential for complete thermal ablation of solid tumors following a systemic injection of AuNPs (Fig. 1d (i, ii)). Following these studies, AuroLase ${ }^{\circledR}$ entered in two separate clinical trials (Table I). The first, which was last updated in September 2014 (NCT00848042), has been reported as being completed for the treatment of patients with refractory and/or recurrent tumors for head and neck cancer (www.clinicaltrials.gov). Another clinical trial, which is currently active but not recruiting, is investigating AuroLase ${ }^{\circledR}$ for the treatment of primary and/or metastatic lung tumors where the airway is obstructed.

AuroLase ${ }^{\circledR}$ is an example of an inorganic nanoparticle that has been systematically investigated and shown efficacy in tumor ablation at the preclinical stage and is currently being investigated in the clinic. AuroLase ${ }^{\circledR}$ provides many advantages for tumor treatment. Most notably, AuroLase ${ }^{\circledR}$ can provide a tumor treatment that avoids many of the systemic side effects associated with more traditional tumor therapies $(32,33)$ (e.g., chemotherapy) by providing localized tumor treatment which selectively treats the tumor while also limiting the damage to healthy tissue. As such, AuroLase ${ }^{\circledR}$ provides a means of addressing a clear limitation in current tumor therapy and thus is a vehicle to provide a therapy that is otherwise not currently possible. At the preclinical stage, AuroLase is also being investigated as a supplemental therapy for both radiation therapy (34) and imaging (35) and for a select few other commercial applications $(36,37)$. AuroLase ${ }^{\circledR}$ still faces certain technical and biological challenges before clinical approval, such as proving that this system can be used intravenously and target tumors utilizing the enhanced permeation and retention (EPR) effect, in lieu of an active targeting moiety. The EPR effect is proven to aid in the tumor accumulation of nanoparticles in preclinical animal studies but is less validated in a clinical setting (38), and thus, relying on the EPR's targeting effect may present a challenge for AuroLase $\AA$. Furthermore, since AuroLase $\AA$ is a local therapy designed to treat solid tumors at the tumor site, translating this technology to treat systemic malignancies may prove difficult.

In another example, AuNPs capable of treating acne are being developed by Sebacia Inc. The particles being developed are $\sim 150 \mathrm{~nm}$ silica-gold nanoshells, coated with PEG to increase stability, and specifically tuned to absorb NIR light and NIR laser irradiation (Fig. 2a) to treat acne by disrupting overactive sebaceous glands in the skin (39). The AuNPs, dubbed Sebashells, are (i) topically administered to sites of acne, (ii) delivered deep into the sebaceous ducts via lowfrequency ultrasound, and (iii) stimulated via NIR laser to induce focal thermolysis of sebaceous glands, effectively treating acne (Fig. 2b). In a recently published study, Sebashells showed the capability to penetrate into the sebaceous glands of porcine skin in vitro (Fig. 2c) (39). Low-frequency ultrasound increased delivery of Sebashells into deep areas of sebaceous glands over 15-fold as compared with a standard method of massaging them into the skin. Once penetrated into the sebaceous gland, Sebashells were 
a
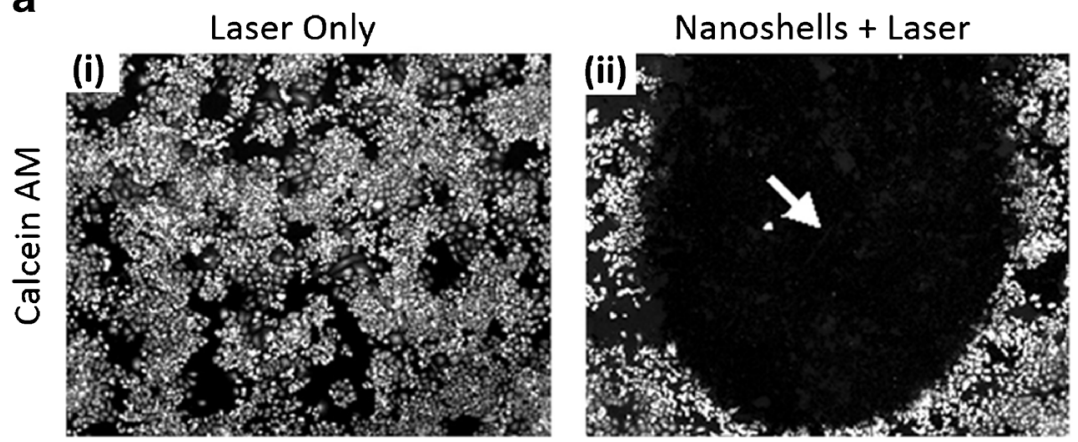

b
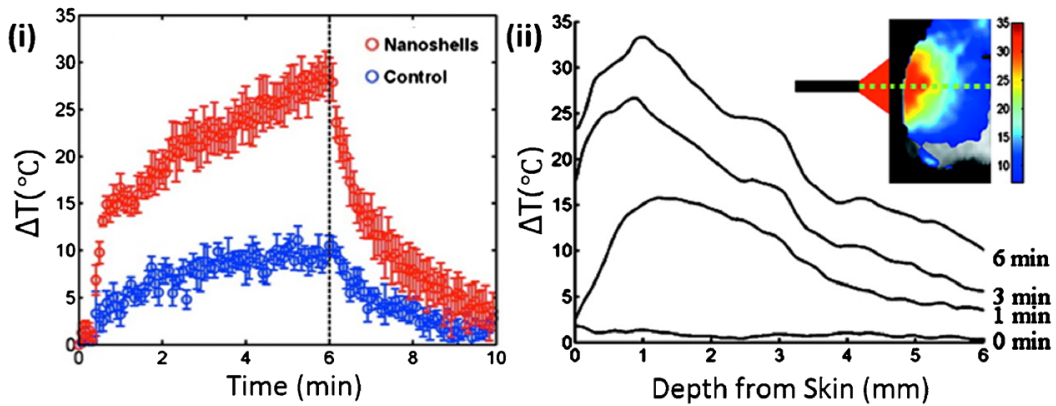

C

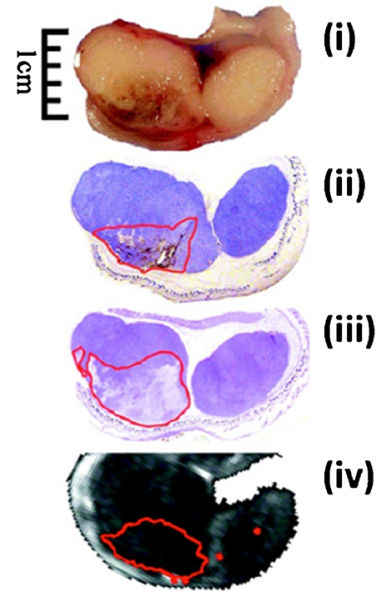

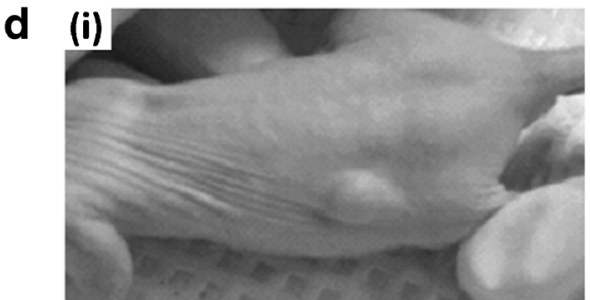

(ii)

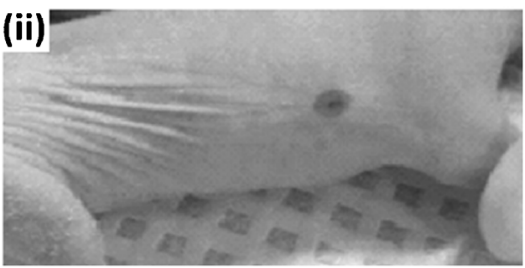

Fig. 1. Preclinical performance of AuroLase ${ }^{\circledR}$ AuNPs currently undergoing clinical trials. a Membrane-viability-stained (calcein $A M$ ) breast cancer cells following laser exposure $i$ without nanoshells and $i i$ with nanoshells. The arrow in (ii) represents the area of dead cells that were exposed to both nanoshells and the laser. b Temperature change following NIR-irradiation of nanoshells in vivo: $i$ as a function of time (nanoshells group: red circles, control group with no nanoshells: blue circles) and ii as a function of tissue depth (inset, heat map). c Antitumor effect of NIR-stimulated nanoshells treatment: $i$ gross tumor images showing hemorrhaging, ii nanoshell localization (red outline) following silver staining, iii tissue damage as shown by hematoxylin and eosin staining, and $i v$ magnetic resonance temperature imaging suggesting areas of irreversible thermal damage. d Prostate tumor regressions following a single treatment of an intravenous: $i$ saline injection with laser treatment or ii nanoshell injection with laser treatment. a-c Adapted from (29), copyright (2003) National Academy of Sciences, U.S.A. d Adapted from (31), copyright (2008), with permission from Elsevier

stimulated with NIR laser and were capable of inducing deep glandular thermolysis (Fig. 2d). Following these in vitro tests to confirm proof of concept, Sebashells were tested in vivo in a porcine model to examine the safety of ultrasound and laser exposure, both independent and in combination. By using laser parameters which are common to dermatological applications (e.g., hair removal), no long-term skin safety issues were visually noted. In a pilot human study, Sebashell delivery was performed as depicted (Fig. 2b), and thermolysis in humans as a function of ultrasound exposure time was determined (Fig. 2e). This clinical data was analyzed from skin biopsies following Sebashell application, ultrasound 
Table I. List of Clinical Trials for inorganic nanoparticles which are currently active or recruiting (retrieved from www.clinicaltrials.gov)

\begin{tabular}{lc}
\hline Name & Material/functionality \\
\hline Feraheme $囚 ;$ & Iron oxide nanoparticles (coated with \\
Rienso®; & polyglucose sorbitol carboxymethylether). \\
Ferumoxytol & Magnetic-field responsive nanoparticles \\
& for MRI imaging. Investigated in many \\
& clinical trials in combination with \\
& various targeting agents and other \\
& imaging agents.
\end{tabular}
fluorophore, PEG coating, and
radiolabeled cRGDY targeting peptide. PET and flourescent imaging

NBTXR3

Crystalized hafnium oxide nanoparticles. X-ray responsive

Sebacia Microparticles

Gold particles with silica core. Laser responsive

Sienna $+{ }^{\circledR}$

Silver

Magnablate

Sensors

functionalized with gold nanoparticles Buckypaper
Iron oxide particles (coated with carboxydextran). Magnetic responsive particles use with SentiMag ${ }^{\circledR}$ device

Nanosilver flouride. Silver nanoparticles added to fluor varnish

Iron nanoparticles. Magnetic-field responsive for thermal ablation

Organic functionalized gold nanoparticles

Macroscopic aggregate of carbon nanotubes

Application/indication

Imaging: Multiple sclerosis and demyelinating diseases. Bone sarcomas and osteomyelitis. Triple negative breast, non small cell lung, colorectal, pancreatic, ovarian, gastric, head and neck, lymph node, prostate, bladder, kidney, and thyroid cancers. Neuroinflammation in epilepsy. Type 1 diabetes progression. Peripheral arterial disease. Heart inflammation. Myocardial infarction. Carotid atherosclerosis. Whole body imaging for cancer staging. Kidney transplant rejection

Anemia: Pediatric patients with chronic kidney disease. Peritoneal dialysis patients. Preoperative management in patients undergoing cardiac surgery

Lymph node imaging

Thermal ablation of solid tumors: Head/neck cancer. Primary and/or metastatic lung tumors

Imaging: Melanoma and malignant brain tumors. Intraoperative sentinel lymph node mapping

ClinicalTrials.gov identifier

Imaging: NCT00978562,

NCT00103038, NCT01973517,

NCT01336803, NCT01770353, NCT00659126, NCT02084303,

NCT01895829, NCT01815333,

NCT01521520, NCT02189889,

NCT02141490, NCT01927887,

NCT02253602, NCT00707876,

NCT02319278, NCT01995799,

NCT01674257, NCT01542879,

NCT02359097, and

NCT02006108

\author{
Anemia: NCT01264679, \\ NCT01942460, \\ and NCT02189889
}

NCT00416455

NCT00848042; NCT01679470

NCT01266096; NCT02106598

Enhanced radiotherapy for tumor treatment

Treatment of moderate

to moderately

severe inflammatory acne vulgaris

Mark and locate cancerous

lymph nodes prior to surgery

NCT01433068; NCT01946867

NCT02219074; NCT02217228

NCT01790399; NCT02249208

Prevent dental biofilm growth.

Dental remineralization

Prostate cancer

NCT01950546; NCT01975545

NCT02033447

Detection of gastric lesions

NCT01420588

Fixing method for treatment of abdominal wall hernias
NCT02328352 stimulation and NIR laser treatment (39). These results highlight the importance of the contribution of lowfrequency ultrasound in increasing follicular damage, which likely stems from the increased penetration of Sebashells. Low-frequency ultrasound has shown utility in various applications in transdermal delivery (40), some of which have been approved by the FDA (41), which bodes well for the
Sebacia's ultrasound-mediated Sebashell delivery system. It should be noted that this study did not investigate efficacy in treating acne, however in unpublished work, Sebacia has recently reported positive results from two separate clinical studies focused on acne treatments (42).

A press release on 28th January 2015 stated that Sebashells were successful in providing a significant reduction 
a

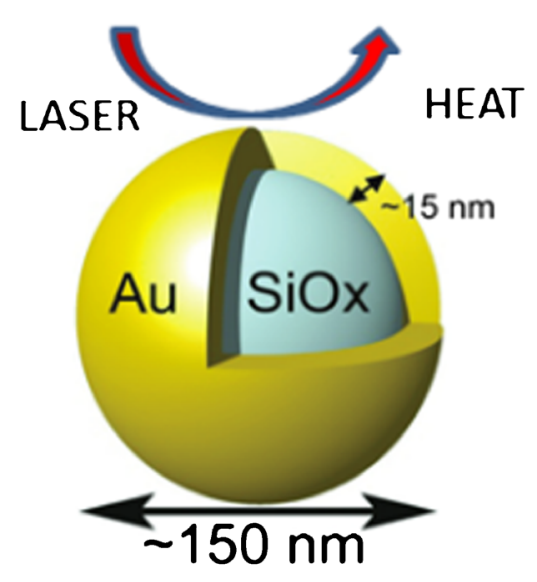

b

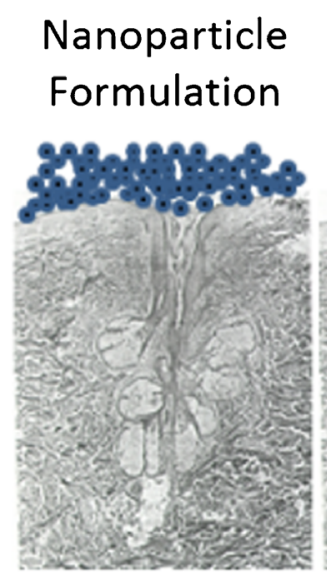

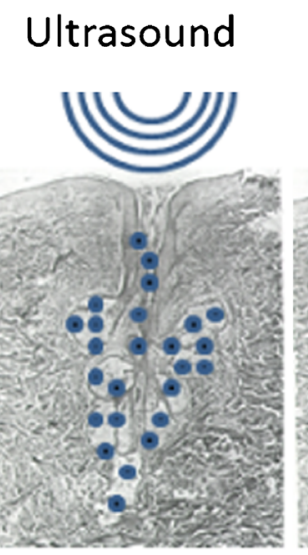
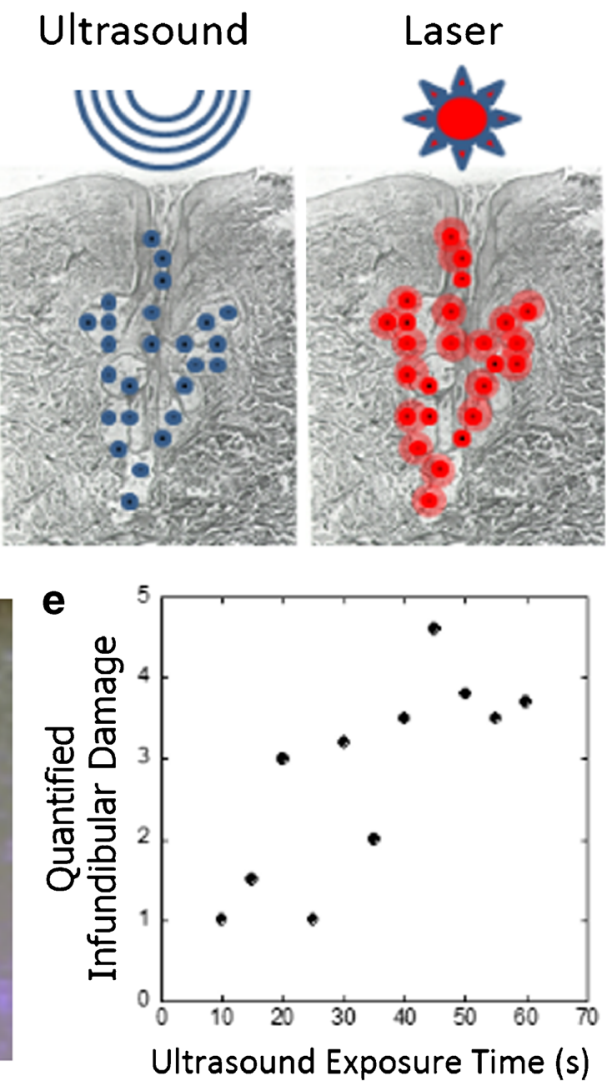
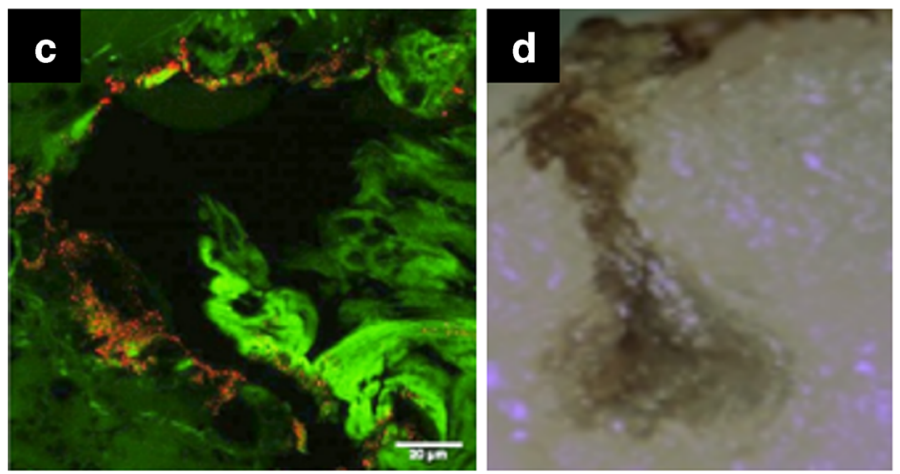

Fig. 2. Preclinical and clinical performance of Sebashell AuNPs currently undergoing clinical trials. a NIR light absorption of Sebashells produces heat. b Schematic illustrating the topical application of Sebashells, ultrasound-mediated penetration of Sebashells, and NIR-laser-induced ablation of sebaceous glands using Sebashells. c Two-photon-induced photoluminescence imaging shows the localization of Sebashells in a sebaceous gland in porcine skin in vitro. d Deep glandular thermolysis following NIR-induced ablation of sebaceous gland localized Sebashells. e Clinical data in humans showing thermolysis as a function of ultrasound exposure. a-e Adapted from (39), copyright (2015), with permission from Elsevier

in both the occurrence and appearance of inflammatory acne lesions (42). Furthermore, the report states that the treatment was well tolerated. Additional clinical studies are currently underway (Table I). These clinical studies are focused on investigating the safety and efficacy in treating acne using Sebashells with NIR laser stimulation. Sebacia's Sebashells provide many advantages over standard treatments for acne, such as avoiding systemic side effects associated with standard acne treatments. Furthermore, Sebashells potentially offer a long-term solution for acne, as it is designed to treat acne by impacting overactive sebaceous glands. If successful, recurrence of acne should be limited.

\section{Challenges and Opportunities: Translation of AuNPs}

AuNPs represent an exciting class of inorganic nanoparticles with the potential to shift the paradigm of treatment of cancer and other diseases. It is clear that AuNPs can perform functions that few other classes of nanoparticles can execute, and as a result, AuNPs offer therapeutic and diagnostic opportunities that cannot be traditionally provided. Since many cancers build resistance to certain drugs (43) and patients can also suffer from dose-limiting toxicities, AuNP therapies can uniquely complement these existing therapies and likely enhance clinical cancer care. Furthermore, the unique SPR of AuNPs can be used to facilitate on-demand release of loaded drugs or cargo at the target site, a task that has proven exceedingly challenging for organic nanoparticles to accomplish even in preclinical studies. While many of these advantages illustrate the unique potential AuNPs possess, in some ways, they also present unique challenges that have not been encountered by other technologies in the clinic. One of the biggest challenges facing AuNPs from entering the clinic is tuning and optimizing surface and physical properties of AuNPs to ensure maximum functionality. Many preclinical studies have focused on the role that size and shape play on modulating AuNPs SPR and subsequently their performance $(17,19)$. However, these modifications need to be investigated at the biological level as it is widely accepted that size and shape of nanocarriers can dramatically alter biological function and fate $(44,45)$. The use of small animal models as the main preclinical model prior to clinical studies further complicates this, as small animals cannot accurately represent a human. Certain studies, however, are utilizing larger animals such as dogs in clinical trials. One key study, using a rod-shaped AuNP system for photothermal imaging and 
therapy known as Pandia ${ }^{\circledR}$, showed complete destruction of cancers in all cases (46).

Another significant issue, which faces both locally and systemically administered AuNPs, is determining their biological fate and long-term biocompatibility. Since countless preclinical studies reporting on cellular interactions, biodistribution and subsequent clearance of AuNPs cannot be normalized with respect to experimental conditions and, especially in the case of gold nanoparticles, particle design (e.g., size, shape, and charge, to name a few), general conclusions are difficult to claim even at the preclinical level. As a result, these parameters need to be systematically investigated at the preclinical level, and at the clinical level where appropriate, to elucidate fundamental information about AuNPs biodistribution, toxicity, and biocompatibility in order to maximize chances for clinical success. Even still, efforts on drawing these conclusions (47) and comparing various studies can help direct current and future studies, both preclinical and clinical.

\section{IRON OXIDE NANOPARTICLES}

\section{Background and Successes in Preclinical Studies}

Iron oxide nanoparticles (IONPS), either superparamagnetic iron oxides (SPIO) or ultrasmall superparamagnetic iron oxides (USPIO), are one of the most investigated inorganic particles used for biological applications (48). The utility and potential of IONPs for clinical use has been proven by the many clinically approved products (Table II) and the numerous clinical trials that are currently underway (Table I). The advantages that iron oxide offer stems from their: (i) innate magnetic responsiveness, which can be controlled in a binary manner and leveraged to facilitate particle targeting (49), imaging (50), and localized heating, the latter of which can be applied towards hyperthermia treatments and tumor ablation (51), and (ii) from their innate biocompatibility and biodegradability (52). Of all their proven applications, IONPs have been most utilized as contrast agents for noninvasive diagnostic imaging in combination with magnetic resonance imaging (MRI) $(2,48)$. IONPs are ideal materials as contrast agents since they: (i) possess unique magnetic properties that stem from their ability to enhance proton relaxation in tissues which leads to enhanced MRI images and (ii) are easily modified to tune their physicochemical parameters to function at the cellular level (53). Preclinical applications of IONPs have been very broad and include therapeutic molecule delivery (54), anemia treatment (55), hyperthermia treatment (56), magnetic targeting (49) and thermal ablation treatment of tumors (57). Another application, which takes advantage of iron oxide's magnetic properties, which is beyond the scope of this article, involves the use of magnetic iron oxide particles for either in vitro diagnostics or cell separations (58).

\section{Clinical Trials and Approved Products}

Of all inorganic nanoparticles, IONPs have been tested in the clinic more than any other type (48). In fact, many IONPs have been approved for use in the clinic as diagnostic and imaging agents (Table II). For example, many IONP formulations have been approved by the FDA for imaging of different pathologies, and even for treatment of iron deficiency (Table II). Despite these successes, the majority of approved IONPs have since been discontinued. The specific reasons for discontinuation are not clear for each product. Currently, the most clinically relevant IONP is ferumoxytol, tradename Feraheme ${ }^{\circledR}$ in the US and Rienso ${ }^{\circledR}$ in Europe. Ferumoxytol is developed and distributed by AMAG Pharmaceuticals $\AA$, originally investigated as an MRI contrast agent (59), but was approved for the treatment of iron deficiency in adults with chronic kidney disease in 2009 by the FDA. Interestingly, ferumoxytol is widely explored in numerous clinical studies (Table I) for many other applications including additional treatments for anemia and also for imaging. This section will focus on the clinical applications of ferumoxytol given that it is currently one of the only FDAapproved IONPs that has not been discontinued and the most clinically investigated, for both imaging and anemia (60).

Ferumoxytol are USPIO nanoparticles, approximately $17-31 \mathrm{~nm}$ in diameter $(61,62)$, coated with polyglucose sorbitol carboxymethylether. Intravenous iron treatments are often used in severely anemic patients, though they raise certain safety concerns (63), are limited by low doses, and are riddled with many systemic side effects (64) which all limit further dosing and therefore treatment (65). In early clinical trials, ferumoxytol showed advantages over traditional iron treatments, such as improved pharmacokinetic properties and simpler administration methods (66). Furthermore, early studies showed that ferumoxytol was well tolerated both in healthy individuals and in hemodialysis patients, even when given as a bolus (66). Follow-up clinical trials investigated both the safety and efficacy in anemic chronic kidney disease patients, who frequently require intravenous iron treatments. In this study, it was shown that ferumoxytol was safe with no serious adverse events, capable of increasing iron stores and was effective in increasing hemoglobin response (67). In a larger, Phase III trial, ferumoxytol showed effective treatment of iron deficiency anemia in patients with CKD with minimal adverse events $(10.6 \%)$, and notably provided up to 1 gram of iron with two intravenous injections as opposed to 5 to 8 doses of standard treatment via significantly slower infusion (68). Ferumoxytol was approved in 2009 for the treatment of iron deficiency anemia in adult patients with chronic kidney disease. There are currently at least 3 clinical trials investigating the use of ferumoxytol to treat anemia (Table I) in pediatric patients with chronic kidney disease, patients undergoing peritoneal dialysis and patients undergoing cardiac surgery.

Ferumoxytol is also being studied in a number of clinical trials (Table I) for the imaging of a variety of diseases and conditions, ranging from: multiple sclerosis to numerous cancers (e.g. prostate, bladder, breast, lung, ovarian, to name a few) to heart conditions to type 1 diabetes. Here, we will highlight a few of these recent examples. The first study directly compared ferumoxytol and gadoteridol, a commonly used MRI contrast agent, in a patient with glioblastoma multiforme (69). One of the main issues with gadoteridol is that this class of contrast enhancing agents are connected to nephrogenic systemic fibrosis, which has limited use of gadoteridol agents in patients with low glomerular filtration rates (70). As such, ferumoxytol, being FDA-approved for 
Table II. List of FDA-approved inorganic nanoparticle products

\begin{tabular}{|c|c|c|c|}
\hline Name & Material/functionality & Application/indication & Approval date \\
\hline Feridex I.V.®; Endorem $®$ & $\begin{array}{l}\text { Iron oxide nanoparticles } \\
\text { (coated with dextran) } \\
\text { Magnetic-field responsive for MRI } \\
\text { imaging }\end{array}$ & Imaging of liver lesions & $\begin{array}{l}\text { FDA approved (1996). } \\
\text { Discontinued (2008) }\end{array}$ \\
\hline $\begin{array}{c}\text { Resovist }{ }^{\circledR} ; \\
\text { Cliavist }\end{array}$ & $\begin{array}{l}\text { Iron oxide nanoparticles } \\
\quad \text { (coated with carboxydextran) } \\
\text { Magnetic-field responsive for MRI } \\
\text { imaging }\end{array}$ & Imaging of liver lesions & $\begin{array}{l}\text { EMA approved (2001). } \\
\text { Discontinued (2009) }\end{array}$ \\
\hline $\begin{array}{l}\text { Gastromark }^{\mathrm{TM}} ; \\
\text { Lumirem }{ }^{\circledR}\end{array}$ & $\begin{array}{l}\text { Iron oxide nanoparticles } \\
\quad \text { (coated with silicone) } \\
\text { Magnetic-field responsive } \\
\text { nanoparticles for MRI imaging }\end{array}$ & $\begin{array}{l}\text { Enhance bowel } \\
\text { imaging (oral administration) }\end{array}$ & $\begin{array}{l}\text { FDA approved (1996). } \\
\text { Discontinued (2012) }\end{array}$ \\
\hline $\begin{array}{l}\text { Ferumoxtran-10; } \\
\text { Combidex }{ }^{\circledR} ; \\
\text { Sinerem }{ }^{\circledR}\end{array}$ & $\begin{array}{l}\text { Iron oxide nanoparticles } \\
\text { (coated with dextram) } \\
\text { Magnetic-field responsive for } \\
\text { MRI imaging }\end{array}$ & $\begin{array}{l}\text { Lymph node metastases } \\
\text { imaging }\end{array}$ & $\begin{array}{l}\text { Approved in some } \\
\text { European countries. } \\
\text { Application } \\
\text { withdrawn from EMA } \\
\text { (Sinerem 2007). } \\
\text { Application } \\
\text { withdrawn } \\
\text { from FDA (2005) }\end{array}$ \\
\hline $\begin{array}{l}\text { Feraheme®; Rienso } ® ; \\
\quad \text { Ferumoxytol }\end{array}$ & $\begin{array}{l}\text { Iron oxide nanoparticles } \\
\text { (coated with polyglucose } \\
\text { sorbitol carboxymethylether) }\end{array}$ & $\begin{array}{l}\text { Treatment of iron deficiency } \\
\text { in adults with chronic kidney disease }\end{array}$ & FDA approved (2009) \\
\hline
\end{tabular}

anemia treatment and showing very little toxicity and association with adverse events, is an attractive candidate to address this issue provided that it can suitably enhance MRI in key instances. Background precontrast, gadoteridol and 24 hour lag ferumoxytol T1-weighted and T2-weighted images were taken of the patient's brain tumor (Fig. 3a-f). This patient showed ferumoxytol enhancement in areas that did not appear in the gadoteridol contrast images. This enhancement was attributed to the presence of inflammatory cells, since ferumoxytol will be internalized by macrophages, by virtue of being a nanoparticle (69). Most recently, ferumoxytol has been clinically investigated to capture the initiation and progression of type-1 diabetes, which has proven to be especially challenging to visualize in a noninvasive way. By facilitating the imaging of inflamed pancreatic lesions following local macrophage uptake of ferumoxytol, this approach was validated both in mouse models and a pilot human study (71). Notably, this study showed that ferumoxytol exhibited higher nanoparticle accumulation in type- 1 diabetes patients as compared with healthy patients (Fig. 3g) (71). This study highlights the potential of using ferumoxytol to visualize the progression of type- 1 diabetes, and more importantly, the potential to leverage this method to track responses to type- 1 diabetes therapies.

At the preclinical level, ferumoxytol is being utilized for a variety of other applications including PET imaging following radiolabeling of ferumoxytol (72), labeling cells in vivo for MRI when formulated with heparin and protamine (73), and using ferumoxytol to carry chemotherapeutic drugs for more effective treatment in vivo as compared with free drugs alone (74), to name a few. Ferumoxytol is being investigated in many other clinical trials focused on imaging numerous pathologies (Table I), and is, in some cases, showing enhanced utility as compared with standard imaging agents. At the moment, ferumoxytol is one of the only FDAapproved iron oxide nanoparticles and is certainly the most investigated one that is still in production. Because of this, and because of ferumoxytol's high biocompatibility, ferumoxytol is receiving more attention than any other iron oxide particle has in the past. The advantages of this are that ferumoxytol is being well characterized in both preclinical and clinical studies, and it can potentially make a rapid impact in the clinic.

\section{Challenges and Opportunities: Translation of Iron Oxide NPs}

IONPs benefit most from their material composition, since their material properties facilitate and enhance magnetic imaging. As a therapeutic, IONPs are well suited to treat anemia, given that following degradation they can supply patients with iron. In addition to this, IONPs have the potential to utilize their material properties further and offer magnetic target or even ablative properties. With these other functions in mind, IONPs could be used to: (i) enhance targeting to diseased tissues via magnetic field, (ii) deliver loaded drugs $(51,54)$ to this target site, and (iii) be activated externally to destroy surrounding tissue, effectively providing a targeted combination therapy. Many of these advantages present biological challenges. For example, while IONPs are investigated for tumor treatment either via drug treatment or thermal ablation, these therapies will be limited to local treatment of solid tumors. As stated earlier, a high percentage of approved IONPs have been discontinued, and unfortunately, scientifically reliable reasons are not available. Still, this raises a concern for current and future IONPs of clinical relevance. 
Precontrast- $T_{1} w \& T_{2} w$
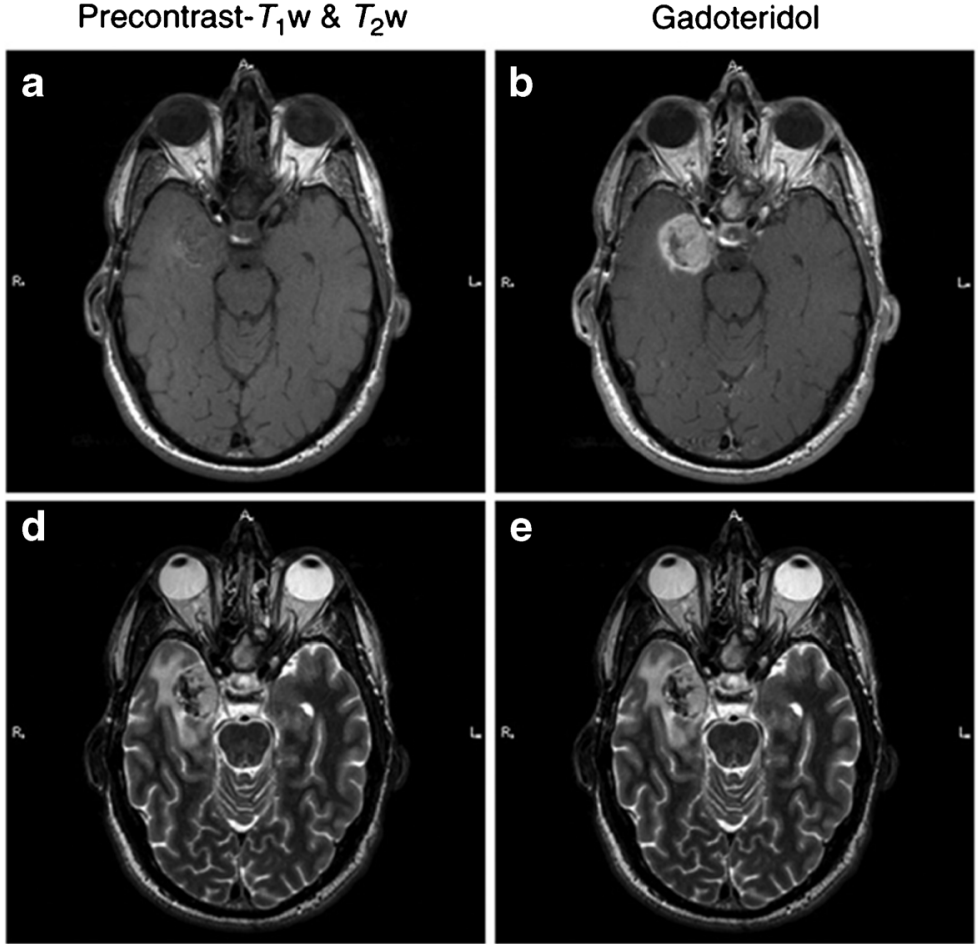

24-h ferumoxytol
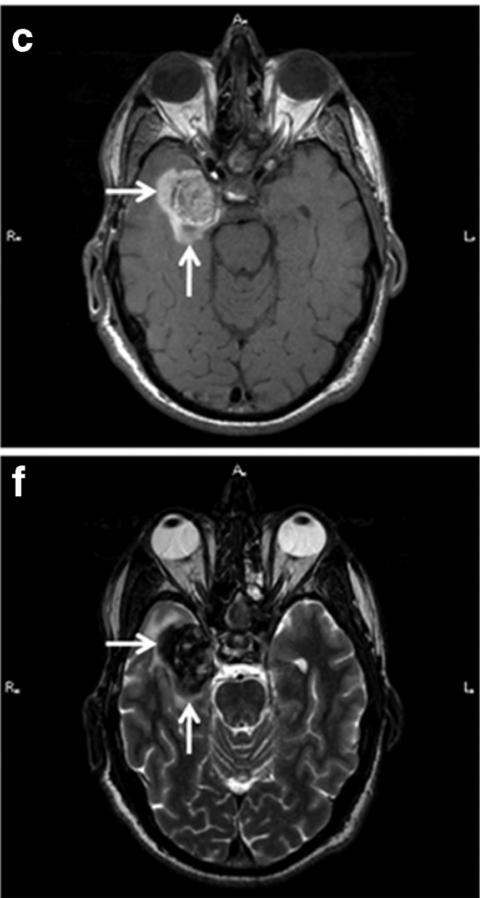

g Type 1 Diabetes

Control

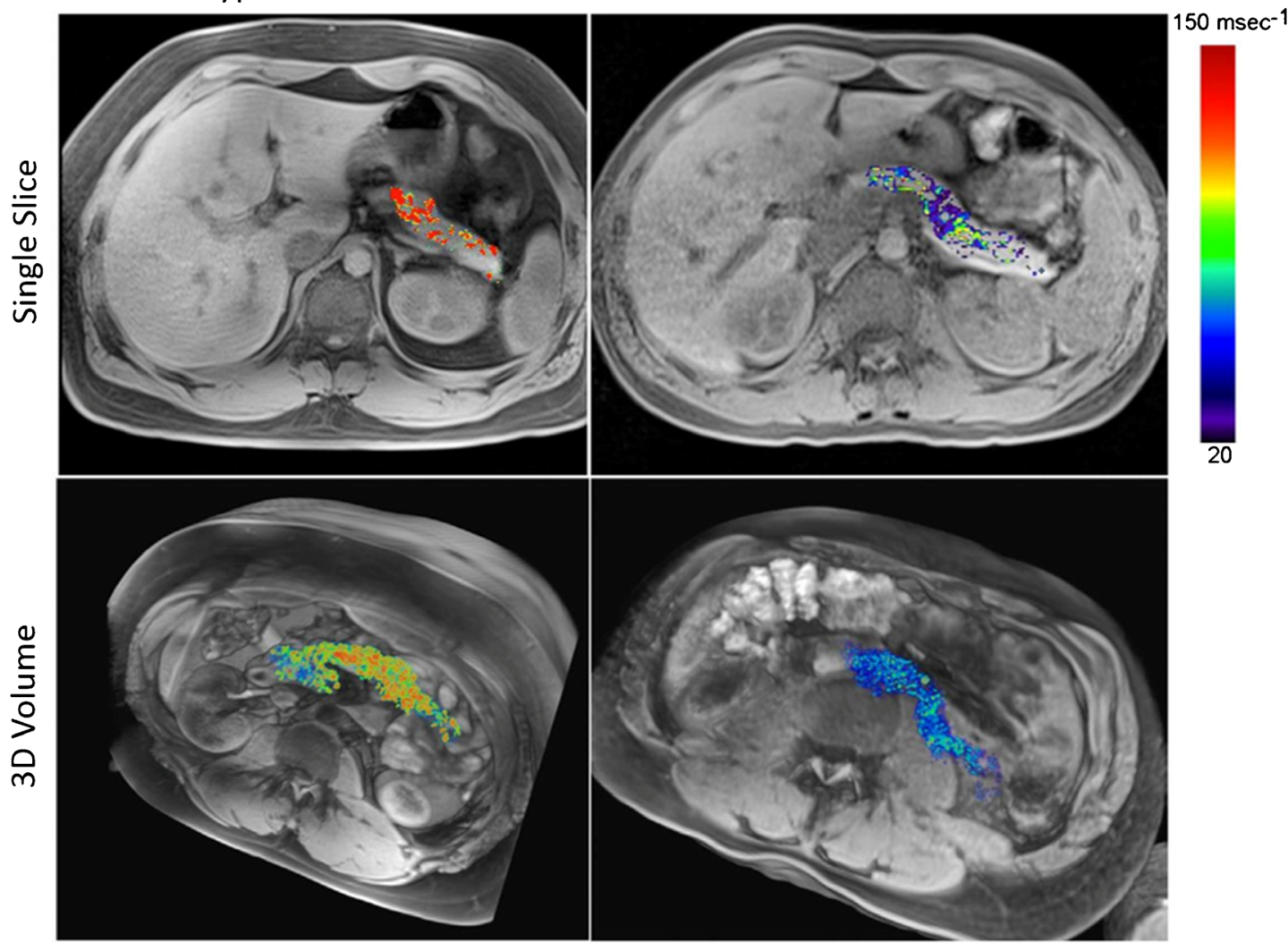

Fig. 3. Clinical pathological imaging using ferumoxytol nanoparticles. MRI of patient with a known glioblastoma multiforme. T1-weighted MRI images: a precontrast, b gadoteridol enhanced, and $\mathbf{c}$ 24-h post-ferumoxytol enhanced. T2weighted MRI images: d precontrast, e gadoteridol enhanced, and $\mathbf{f} 24-\mathrm{h}$ post-ferumoxytol enhanced. White arrows indicate enhancement regions present in ferumoxytol groups but not in gadoteridol groups. $g$ Ferumoxytol MRI in a representative patient with type-1 diabetes (left) and a non-diabetic control patient (right). Single slices (top) and 3D volumes (bottom) show increased ferumoxytol accumulation in a diabetic patient as compared with control. a-f Reprinted from (69), by permission of Oxford University Press. g Adapted from (71) 


\section{SILICA NANOPARTICLES}

\section{Background and Successes in Preclinical Studies}

Silica, or silicon dioxide $\left(\mathrm{SiO}_{2}\right)$, nanoparticles (SNPs) are widely investigated for applications in drug delivery since it is possible to precisely tune their physicochemical parameters for specific biological applications. Physically, it is possible to control the size, shape, and porosity (e.g., mesoporous SNPs) of SNPs (75). The chemical properties of SNPs can also be modified in the form of surface modifications $(75,76)$, which can allow for conjugation of various stealth or targeting ligands. Many of these physicochemical modifications have been shown to independently influence circulation $(77,78)$, targeting (79), drug loading and release (80), and internalization by cells $(81,82)$ of intravenously administered nanoparticles. Many of these modifications can be introduced given the advanced synthesis techniques used for synthesizing SNPs (83), such as the Stöber method (84) or liquid-crystal templating (85), which other drug delivery nanoparticle systems cannot take advantage of. SNPs also benefit from limited toxicity and favorable biodegradability (86). SNPs ability to store and release a variety of drugs are perhaps the most attractive feature of SNPs. Specifically, SNPs offer unmatched surface area for drug storage, which provides a unique opportunity for the incorporation of hydrophilic (87) or hydrophobic drugs, the latter of which has proven difficult for other nanoparticle delivery systems (88). For these reasons, SNPs are extensively used and investigated at the preclinical stage and have been used in many therapeutic and diagnostic applications, including imaging (89), gene transfection vectors for cellular uptake (90), and stimuli-responsive delivery (91). While many SNPs are used in combination with other inorganic materials (e.g., gold as in AuroLase ${ }^{\circledR}$ highlighted above), this section focuses on SNPs that utilize their silica components beyond that of a template.

\section{Current Clinical Trials}

Nanoparticle drug delivery systems predominately comprised of SNPs have not yet made significant impact in the clinic, although one SNP is currently being investigated in clinical trials, which utilizes SNPs for imaging and diagnostics of tumors, has made significant progress towards approval. Cornell Dots (C-Dots) are hybrid silica nanoparticles that are used for enhancing standard positron emission tomography (PET)-optical dual-modality imaging, which is an imaging technique with many advantages over traditional CAT and MRI scans. Developed around 10 years ago, the original CDot formulation was synthesized via a modified Stöber method which yielded $30 \mathrm{~nm}$ diameter fluorescent core-shell SNPs that were 20 times brighter than the constituent fluorophore (92). In a follow-up study, the particle scaffold was modified from the original template to consist of: (i) $\sim 7 \mathrm{~nm}$ diameter final particle size to facilitate renal excretion as shown in a previous study (Fig. 4a (i, ii)) (93), (ii) a nearinfrared Cy5 fluorophore to optimize fluorescence imaging, (iii) a PEG coating to endow immune system avoidance, in particular avoiding opsonization and subsequent internalization by macrophages in the liver (Fig. 4a (i, ii)), and (iv) a ${ }^{124}$ I-radiolabeled cRGDY peptide that functions as both the radiolabeled molecule that facilitates PET imaging and as the targeting peptide to improve targeting and accumulation in $\alpha \nu \beta 3$ integrin expressing tumors (94) (Fig. 4b). In the first in vivo study utilizing this C-Dot formulation, the C-Dots were shown to have utility in real-time and intraoperative detection (95) and imaging of nodal metastases, tumor targeting, and lymphatic drainage patterns (94). Around the time of this publication (94), C-Dots received approval for a first-in-man clinical trial for imaging of cancer in patients with metastatic melanoma.

In this clinical trial, the goal was to test C-Dot safety, since C-Dots had not been previously used in humans. As such, this clinical trial focused on a small number of patients $(n=5)$ with limited life expectancy before moving forward with a larger clinical study focused on dose escalation to optimize tumor-targeting and accumulation. Despite the focus being on safety, the results of this study showed that C-Dots were capable of imaging cancer in this limited number of patients with metastatic melanoma (89). C-Dots were shown to: (i) be well tolerated with no reported toxic or adverse events, (ii) be stable in vivo, (iii) provide consistent pharmacokinetic patterns, and (iv) be capable of imaging lesions, including metastatic lesions, in distinct areas of the body. Effective doses of C-Dots used in this study were comparable with commonly used diagnostic radiotracers. Lack of clinical symptoms in blood/urine samples were used to assess safety following C-Dot administration. In general, this small clinical study showed that C-Dots: (i) did not impair renal function, despite the majority of particles being renally cleared, (ii) did not alter liver function, and (iii) had no adverse events resulting from particle injections. Despite the trial not focusing on tumor targeting, significant uptake and accumulation of C-Dots was seen in multiple patients in both lesions and diseased tissues. In one of the patients, who had anorectal mucosa melanoma with liver metastasis (Fig. 4c (i)), C-Dots could localize and accumulate at the liver metastasis to facilitate PET imaging, 4-h postinjection (Fig. 4c (ii, iii)). In another patient, who presumably had pituitary microadenoma (Fig. 4d (i)), C-Dots accumulated and facilitated PET imaging at the pituitary lesion (Fig. 4d (ii)) and showed increased focal activity when overlaid with MRI imaging (Fig. 4d (iii)). Furthermore, time-lapse imaging of the pituitary lesion highlighted the ability of C-Dots to progressively accumulate in the lesion over time (Fig. 4d (iv)). The next patient, who had impaired renal function and chemotherapy related nephrotoxicity, C-Dot accumulation was seen in the renal cortices for up to 3 days (Fig. 4e), well beyond the renal persistence in other patients which highlights C-Dot specificity for damaged tissue.

C-Dots are currently being investigated in two separate clinical trials (Table I). The first, which is a continuation of the first clinical trial, is designed to investigate the microdosing of C-Dots for imaging patients with melanoma and malignant brain tumors. The second study is designed to facilitate intraoperative sentinel lymph node mapping in patients with head and neck melanoma, prostate, or cervical and uterine cancer. By using C-Dots, this study has the potential to improve cancer detection during surgery, as opposed to standard techniques which detect cancer prior to surgery. In doing so, lymph nodes that contain metastases can be identified and removed during surgery which will facilitate 
a
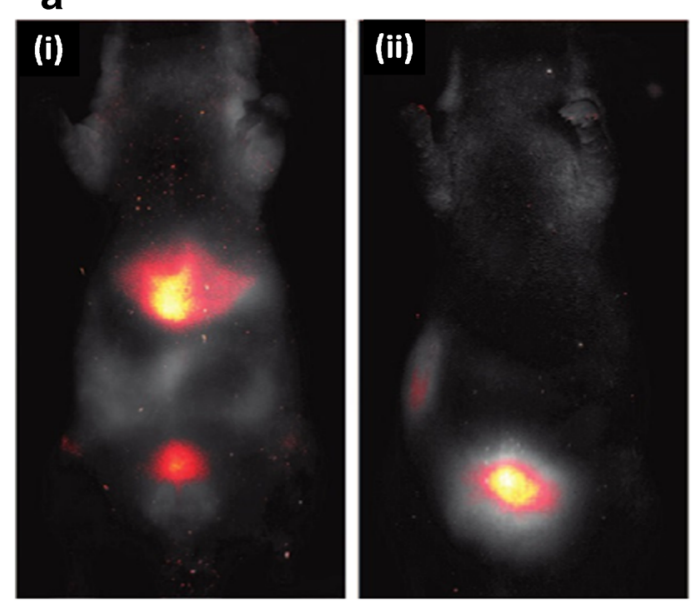

b

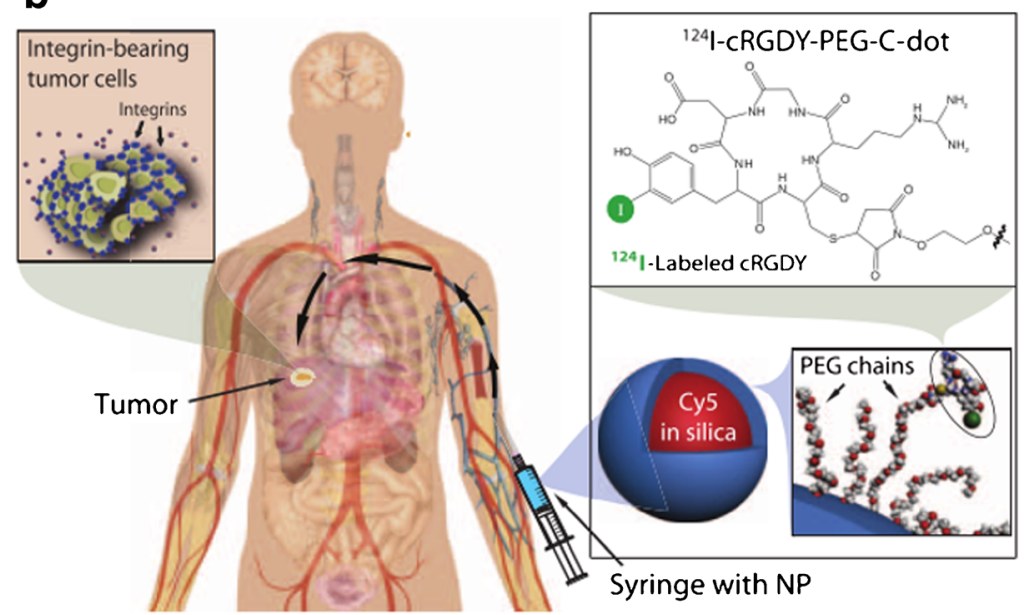

C

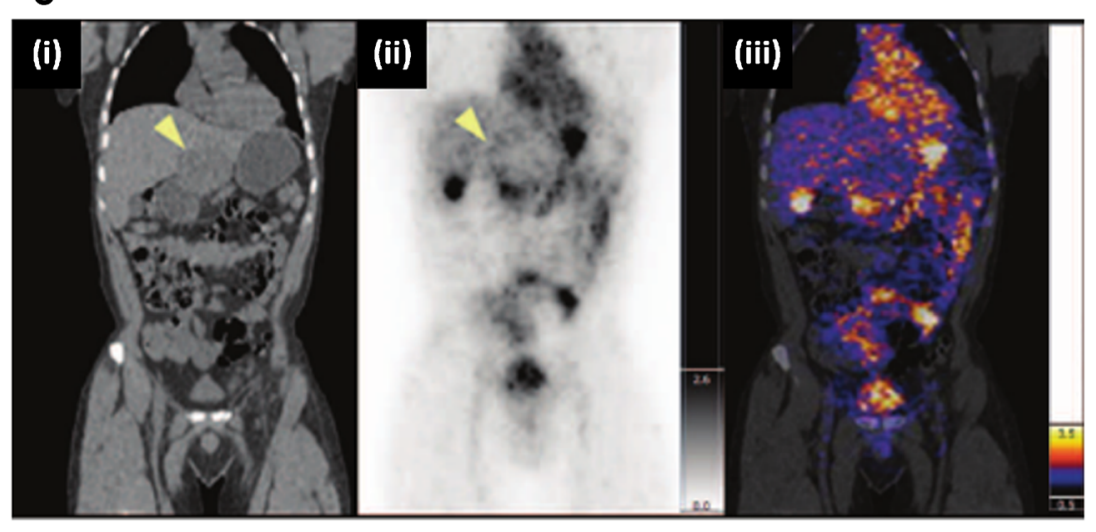

d
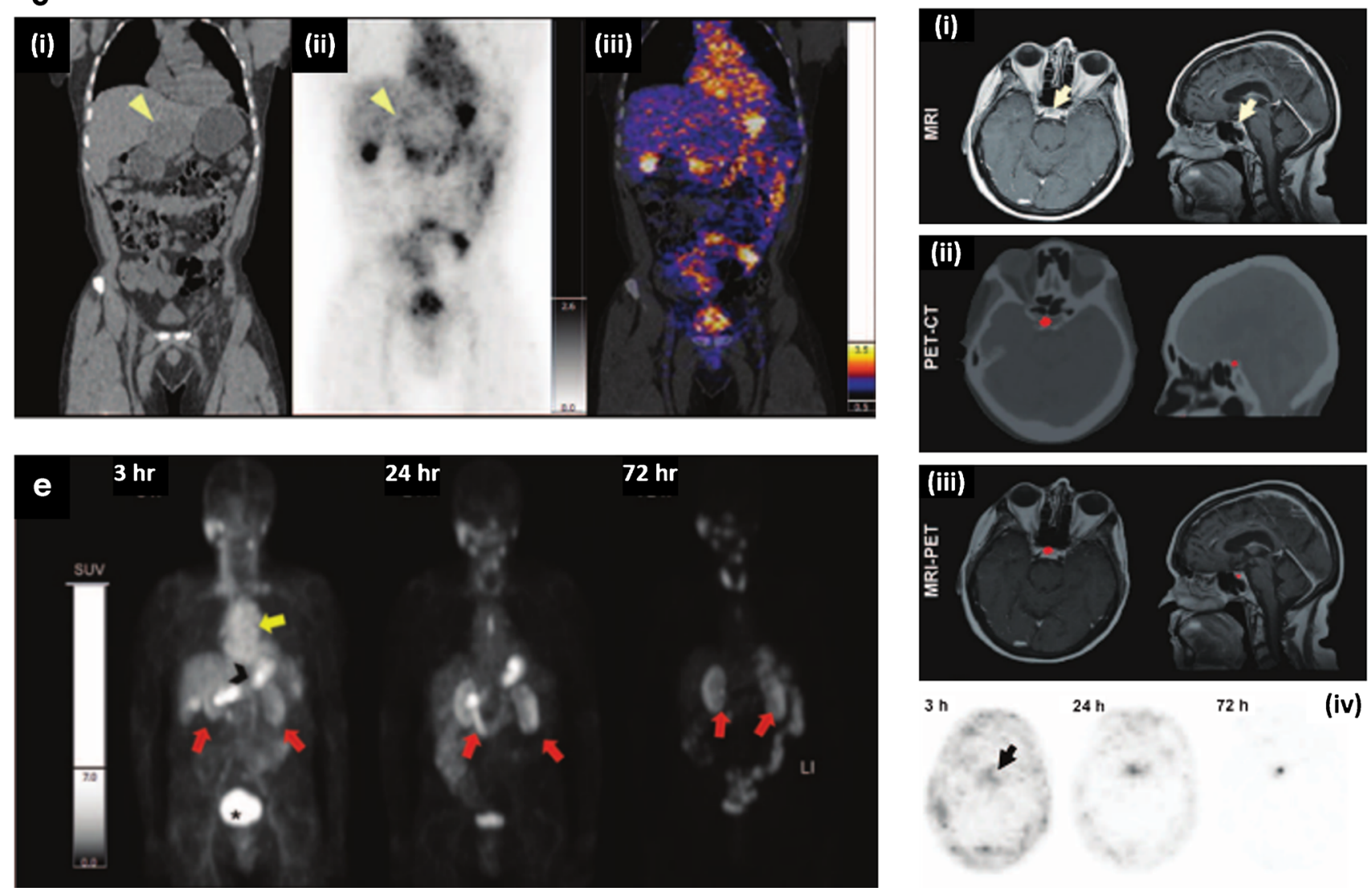

Fig. 4. Preclinical and clinical performance of C-Dots. a In vivo fluorescent imaging in nude mice, 45 min after injection, with: $i$ bare C-Dots, which show accumulation in liver and bladder, and $i i$ PEG-coated C-Dots, which show accumulation only in bladder. PEG coating effectively allows C-Dots to avoid reticuloendothelial clearance organs, such as the liver, and eventually accumulate in the bladder prior to renal clearance. b C-Dot schematic showing: integrin-targeting cRGDY functionality, ${ }^{124}$ I-labeling to facilitate PET imaging, Cy5-loaded core to facilitate fluorescent imaging and PEG coating to allow immune system avoidance. $\mathbf{c} i$ Coronal CT showing left hepatic lobe metastasis (yellow arrowhead), ii coronal PET image, 4-h post-C-Dot injection, showing particle accumulation around tumor periphery (yellow arrowhead), and iii co-registered PET-CT, 4-h post-C-Dot injection, highlighted C-Dot accumulation in tumor periphery in a patient with anorectal mucosa melanoma, with liver metastasis. d $i$ MRI, 72-h post-C-Dot injection, showing a cystic focus in the anterior pituitary gland, $i i$ PET-CT imaging showing C-Dot accumulation in pituitary lesion, and iii MRI-PET showing overlap of C-Dots from PET with pituitary lesion from MRI in a patient with a pituitary microadenoma. $i v$ Time-lapse PET imaging highlighting the progressive accumulation of C-Dot activity up to 72 -h postinjection. e In a patient with impaired renal function and chemotherapy related nephrotoxicity, PET imaging showed C-Dot activity in the cardiac blood pool (yellow arrow), small bowel (black arrowhead), renal cortices (red arrows), and bladder (asterisk); $72 \mathrm{~h}$ later, C-Dot activity remains in the renal cortices. a Adapted with permission from (93). Copyright (2009) American Chemical Society. b-e From (89). Adapted with permission from AAAS 
the removal of more cancerous tissues. C-Dots have been thoroughly investigated and characterized at the preclinical stage and have shown to be capable of improving cancer detection for a variety of cancers, and also intraoperatively. Perhaps the largest impact C-Dots can have in the clinic is by using them intraoperatively to detect metastases in real time, greatly improving surgical outcomes by removing malignancies that are otherwise undetectable. Furthermore, C-Dots possess great potential in improving pre- and postsurgery imaging by providing resolution beyond what CT, MRI and traditional PET scans offer. One of the main advantages of CDots are that they utilize PET imaging, or handheld fluorescent imaging in the intraoperative case, to facilitate malignancy detection which allows C-Dots to take advantage of approved and established technologies to enhance standard care with respect to malignancy detection.

\section{Challenges and Opportunities: Translation of SNPs}

Overall, SNPs can address many of the limitations that current therapeutics and diagnostics have yet to address. For example, SNPs surface can be easily modified to include targeting or imaging agents, as is the case with C-Dots. Their physical parameters can also be modified to facilitate enhanced biological performances. Furthermore, loading of drugs, especially into mesoporous SNPs, can allow levels of loading not achievable by other particle formulations. These loaded drugs can also be triggered for release from mesoporous SNPs via a cap structure that only opens up in response to external stimuli (88). On the other hand, SNPs face many unique challenges that need to be overcome in order to gain clinical approval, and subsequently impact clinical healthcare. One of the main challenges facing SNPs is determining their long-term in vivo fate if they are not cleared by the kidneys. Another challenge, of particular concern for SNPs given the number of unique structural combinations that can be synthesized by tuning physical parameters, is determining the size, shape and porosity of SNPs that confer optimal therapeutic benefits for specific diseases. This challenge will become more apparent following integration, and regulatory approval, of SNPs in the clinic; however, these aspects unique to SNPs should be considered and investigated in order to fundamentally understand how these physical modifications can impact the delivery of SNPs.

\section{CONCLUSIONS}

Inorganic nanoparticles offer clinically unique diagnostic and therapeutic opportunities that polymeric and other traditionally used nanoparticles cannot offer. This potential of inorganic nanoparticles is not limited to topics covered in this review. As an example, inorganic nanoparticles can also be used for ex vivo detection, which is currently being investigated in an active clinical trial that utilizes the breath of patients to detect gastric lesions on an AuNP and carbon nanotube functionalized sensor (Table I). This work builds on preclinical studies that leveraged this same technology to detect lung cancer (96) and gastric cancer (97). In another example, hafnium oxide nanoparticles are being developed by Nanobiotix, which recently completed a clinical trial focused on radiation therapy for treating patients with soft tissue sarcoma. Since then, another clinical trial that is currently recruiting, is investigating these same particles for the treatment of advanced squamous cell carcinoma of the oral cavity or oropharynx (Table I). These hafnium oxide particles, called NBTXR3, utilize external radiation to produce a larger number of cancer cell killing electrons than otherwise possible. As a result, this technology should enhance tumor destruction further than traditional radiation therapy alone could. This technology was shown to have antitumor activity with similar toxicity to standard radiation therapy in animal models (98). Another example are quantum dots, which are utilized for a variety of preclinical in vivo imaging applications (99); although, at the moment, these technologies have been limited to preclinical studies as a result of questions surrounding their toxicity and biocompatibility (100).

The potential to combine components of inorganic nanoparticles with components of organic nanoparticles can provide another avenue into the clinic. The opportunities for this are clear from many of the highlighted examples, however, the highlighted cases covered here have focused on inorganic particle scaffolds with little or minimal organic components as opposed to organic systems modified with inorganic components or nanoparticles. In fact, therapeutic and diagnostic nanoparticles can be developed which are primarily comprised of organic materials but possess enhanced functionalities by including inorganic nanoparticles into their design. A few examples of this include magnetically responsive polymeric particles with IONP functionalization, which can potentially be used either for targeting or imaging purposes. While inorganic nanoparticles have not yet been approved for any drug delivery application, they are widely investigated in the clinic for applications that make use of their unique abilities to respond to external stimuli and leverage local physical changes that can be used therapeutically. Furthermore, the diagnostic opportunities show that inorganic nanoparticles are more robust and versatile, in that they can enhance and improve current imaging and diagnostic techniques, be it MRI or PET scans. In conclusion, inorganic nanoparticles are poised to make a dramatic clinical impact in imaging, diagnostics and certain treatments as they provide functions that are not currently provided in the clinic. Furthermore, these unique functions can potentially supplement and improve current therapies since the mechanisms of treatment are distinct and, in some cases, have proven to be complementary.

\section{ACKNOWLEDGMENTS}

A.C.A. was supported by the National Science Foundation Graduate Research Fellowship under Grant No. DGE1144085 and also by UCSB's Center for Bioengineering under the Mellichamp Fellowship for Graduate Students.

\section{REFERENCES}

1. Huang H-C, Barua S, Sharma G, Dey SK, Rege K. Inorganic nanoparticles for cancer imaging and therapy. J Control Release. 2011;155(3):344-57. 
2. Na HB, Song IC, Hyeon T. Inorganic nanoparticles for MRI contrast agents. Adv Mater. 2009;21(21):2133-48.

3. Li Z, Barnes JC, Bosoy A, Stoddart JF, Zink JI. Mesoporous silica nanoparticles in biomedical applications. Chem Soc Rev. 2012;41(7):2590-605.

4. Giljohann DA, Seferos DS, Daniel WL, Massich MD, Patel PC, Mirkin CA. Gold nanoparticles for biology and medicine. Angew Chem Int Ed. 2010;49(19):3280-94.

5. McCarthy JR, Weissleder R. Multifunctional magnetic nanoparticles for targeted imaging and therapy. Adv Drug Deliv Rev. 2008;60(11):1241-51.

6. Harper BW, Krause-Heuer AM, Grant MP, Manohar M, Garbutcheon-Singh KB, Aldrich-Wright JR. Advances in platinum chemotherapeutics. Chemistry. 2010;16(24):706477.

7. Zhang CX, Lippard SJ. New metal complexes as potential therapeutics. Curr Opin Chem Biol. 2003;7(4):481-9.

8. Feng Q, Wu J, Chen G, Cui F, Kim T, Kim J. A mechanistic study of the antibacterial effect of silver ions on Escherichia coli and Staphylococcus aureus. J Biomed Mater Res. 2001;52:662-8.

9. Anselmo AC, Mitragotri S. An overview of clinical and commercial impact of drug delivery systems. J Control Release. 2014;190:15-28.

10. Wicki A, Witzigmann D, Balasubramanian V, Huwyler J. Nanomedicine in cancer therapy: challenges, opportunities, and clinical applications. J Control Release. 2015;200:138-57.

11. Farokhzad OC, Langer R. Impact of nanotechnology on drug delivery. ACS Nano. 2009;3(1):16-20.

12. Peer D, Karp JM, Hong S, Farokhzad OC, Margalit R, Langer R. Nanocarriers as an emerging platform for cancer therapy. Nat Nanotechnol. 2007;2(12):751-60.

13. Eustis S, El-Sayed MA. Why gold nanoparticles are more precious than pretty gold: noble metal surface plasmon resonance and its enhancement of the radiative and nonradiative properties of nanocrystals of different shapes. Chem Soc Rev. 2006;35(3):209-17.

14. Timko BP, Kohane DS. Prospects for near-infrared technology in remotely triggered drug delivery. Expert Opin Drug Deliv. 2014;11(11):1681-5.

15. Sperling R, Parak W. Surface modification, functionalization and bioconjugation of colloidal inorganic nanoparticles. Philos Trans R Soc A Math Phys Eng Sci. 2010;368(1915):1333-83.

16. Ghosh P, Han G, De M, Kim CK, Rotello VM. Gold nanoparticles in delivery applications. Adv Drug Deliv Rev. 2008;60(11):1307-15.

17. Huang X, El-Sayed MA. Gold nanoparticles: optical properties and implementations in cancer diagnosis and photothermal therapy. J Adv Res. 2010;1(1):13-28.

18. Han G, Ghosh P, Rotello VM. Functionalized gold nanoparticles for drug delivery. 2007.

19. Jain PK, Lee KS, El-Sayed IH, El-Sayed MA. Calculated absorption and scattering properties of gold nanoparticles of different size, shape, and composition: applications in biological imaging and biomedicine. J Phys Chem B. 2006;110(14):723848.

20. El-Sayed IH, Huang X, El-Sayed MA. Selective laser photothermal therapy of epithelial carcinoma using anti-EGFR antibody conjugated gold nanoparticles. Cancer Lett. 2006;239(1):129-35.

21. Tkachenko AG, Xie H, Coleman D, Glomm W, Ryan J, Anderson MF, et al. Multifunctional gold nanoparticle-peptide complexes for nuclear targeting. J Am Chem Soc. 2003;125(16):4700-1.

22. Giljohann DA, Seferos DS, Prigodich AE, Patel PC, Mirkin CA. Gene regulation with polyvalent siRNA-nanoparticle conjugates. J Am Chem Soc. 2009;131(6):2072-3.

23. Wang F, Wang Y-C, Dou S, Xiong M-H, Sun T-M, Wang J. Doxorubicin-tethered responsive gold nanoparticles facilitate intracellular drug delivery for overcoming multidrug resistance in cancer cells. ACS Nano. 2011;5(5):3679-92.

24. Connor EE, Mwamuka J, Gole A, Murphy CJ, Wyatt MD. Gold nanoparticles are taken up by human cells but do not cause acute cytotoxicity. Small. 2005;1(3):325-7.

25. Higby GJ. Gold in medicine. Gold Bull. 1982;15(4):130-40.
26. Flocks R, Kerr H, Elkins H, Culp D. Treatment of carcinoma of the prostate by interstitial radiation with radio-active gold (Au198) a preliminary report. J Urol (US). 1952;68.

27. Abraham E, Peter B, Himmel G. Management of rheumatoid arthritis: rationale for the use of colloidal metallic gold. J Nutr Environ Med. 1997;7(4):295-305.

28. Nanospectra. AuroLase ${ }^{\circledR}$ Therapy 2011. Accessed 12 Jan 2015. Available from: http://www.nanospectra.com/clinicians/ aurolasetherapy.html.

29. Hirsch LR, Stafford RJ, Bankson JA, Sershen SR, Rivera B, Price RE, et al. Nanoshell-mediated near-infrared thermal therapy of tumors under magnetic resonance guidance. Proc Natl Acad Sci U S A. 2003;100(23):13549-54.

30. Schwartz JA, Shetty AM, Price RE, Stafford RJ, Wang JC, Uthamanthil RK, et al. Feasibility study of particle-assisted laser ablation of brain tumors in orthotopic canine model. Cancer Res. 2009;69(4):1659-67.

31. Stern JM, Stanfield J, Kabbani W, Hsieh JT, Cadeddu JA Selective prostate cancer thermal ablation with laser activated gold nanoshells. J Urol. 2008;179(2):748-53.

32. Dearnaley DP, Khoo VS, Norman AR, Meyer L, Nahum A, Tait $\mathrm{D}$, et al. Comparison of radiation side-effects of conformal and conventional radiotherapy in prostate cancer: a randomised trial. Lancet. 1999;353(9149):267-72.

33. Love RR, Leventhal H, Easterling DV, Nerenz DR. Side effects and emotional distress during cancer chemotherapy. Cancer. 1989;63(3):604-12.

34. Diagaradjane P, Shetty A, Wang JC, Elliott AM, Schwartz J, Shentu S, et al. Modulation of in vivo tumor radiation response via gold nanoshell-mediated vascular-focused hyperthermia: characterizing an integrated antihypoxic and localized vascular disrupting targeting strategy. Nano Lett. 2008;8(5):1492-500.

35. Lin AW, Lewinski NA, West JL, Halas NJ, Drezek RA. Optically tunable nanoparticle contrast agents for early cancer detection: model-based analysis of gold nanoshells. J Biomed Opt. 2005;10(6):064035.

36. Goodrich GP, Bao L, Gill-Sharp K, Sang KL, Wang J, Payne JD. Photothermal therapy in a murine colon cancer model using near-infrared absorbing gold nanorods. J Biomed Opt. 2010;15(1):018001.

37. Gobin AM, O'Neal DP, Watkins DM, Halas NJ, Drezek RA, West JL. Near infrared laser-tissue welding using nanoshells as an exogenous absorber. Lasers Surg Med. 2005;37(2):123-9.

38. Prabhakar U, Maeda H, Jain RK, Sevick-Muraca EM, Zamboni W, Farokhzad OC, et al. Challenges and key considerations of the enhanced permeability and retention effect for nanomedicine drug delivery in oncology. Cancer Res. 2013;73(8):2412-7.

39. Paithankar D, Hwang BH, Munavalli G, Kauvar A, Lloyd J, Blomgren $\mathrm{R}$, et al. Ultrasonic delivery of silica-gold nanoshells for photothermolysis of sebaceous glands in humans: nanotechnology from the bench to clinic. J Control Release. 2015;206:30-6.

40. Mitragotri S, Blankschtein D, Langer R. Ultrasound-mediated transdermal protein delivery. Science. 1995;269(5225):850-3.

41. Mitragotri S. Healing sound: the use of ultrasound in drug delivery and other therapeutic applications. Nat Rev Drug Discov. 2005;4(3):255-60.

42. SEBACIA. Sebacia Announces Positive Results of Two Independent Clinical Studies in Acne January 28, 2015. Accessed 27 Feb 2015. Available from: http://www.sebacia.com/media/ SebaciaClinicalPressRelease20150127.pdf.

43. Coley HM. Mechanisms and strategies to overcome chemotherapy resistance in metastatic breast cancer. Cancer Treat Rev. 2008;34(4):378-90.

44. Decuzzi P, Godin B, Tanaka T, Lee S-Y, Chiappini C, Liu X, et al. Size and shape effects in the biodistribution of intravascularly injected particles. J Control Release. 2010;141(3):320-7.

45. Champion JA, Katare YK, Mitragotri S. Particle shape: a new design parameter for micro- and nanoscale drug delivery carriers. J Control Release. 2007;121(1):3-9.

46. Schoen C, London C. Pandia ${ }^{\circledR}$. Nanotechnology for Biomedical Imaging and Diagnostics: John Wiley \& Sons, Inc; 2014. p. 347-72. 
47. Khlebtsov N, Dykman L. Biodistribution and toxicity of engineered gold nanoparticles: a review of in vitro and in vivo studies. Chem Soc Rev. 2011;40(3):1647-71.

48. Laurent S, Forge D, Port M, Roch A, Robic C, Vander Elst $\mathrm{L}$, et al. Magnetic iron oxide nanoparticles: synthesis, stabilization, vectorization, physicochemical characterizations, and biological applications. Chem Rev. 2008;108(6):2064-110.

49. Chertok B, Moffat BA, David AE, Yu F, Bergemann C, Ross $\mathrm{BD}$, et al. Iron oxide nanoparticles as a drug delivery vehicle for MRI monitored magnetic targeting of brain tumors. Biomaterials. 2008;29(4):487-96.

50. Kooi ME, Cappendijk V, Cleutjens K, Kessels A, Kitslaar P, Borgers $\mathrm{M}$, et al. Accumulation of ultrasmall superparamagnetic particles of iron oxide in human atherosclerotic plaques can be detected by in vivo magnetic resonance imaging. Circulation. 2003:107(19):2453-8.

51. Arruebo M, Fernández-Pacheco R, Ibarra MR, Santamaría J. Magnetic nanoparticles for drug delivery. Nano Today. 2007;2(3):22-32.

52. Arbab AS, Bashaw LA, Miller BR, Jordan EK, Lewis BK, Kalish $\mathrm{H}$, et al. Characterization of biophysical and metabolic properties of cells labeled with superparamagnetic iron oxide nanoparticles and transfection agent for cellular MR imaging 1. Radiology. 2003;229(3):838-46.

53. Sun C, Lee JS, Zhang M. Magnetic nanoparticles in MR imaging and drug delivery. Adv Drug Deliv Rev. 2008;60(11):1252-65.

54. Jain TK, Morales MA, Sahoo SK, Leslie-Pelecky DL, Labhasetwar V. Iron oxide nanoparticles for sustained delivery of anticancer agents. Mol Pharm. 2005;2(3):194-205.

55. Ra W, Stark D, Engelstad B, Bacon B, Compton C, White D, et al. Superparamagnetic iron oxide: pharmacokinetics and toxicity. Am J Roentgenol. 1989;152(1):167-73.

56. Laurent S, Dutz S, Häfeli UO, Mahmoudi M. Magnetic fluid hyperthermia: focus on superparamagnetic iron oxide nanoparticles. Adv Colloid Interf Sci. 2011;166(1):8-23.

57. Hilger I, Hiergeist R, Hergt R, Winnefeld K, Schubert H, Kaiser WA. Thermal ablation of tumors using magnetic nanoparticles: an in vivo feasibility study. Investig Radiol. 2002;37(10):580-6.

58. Xu H, Aguilar ZP, Yang L, Kuang M, Duan H, Xiong Y, et al. Antibody conjugated magnetic iron oxide nanoparticles for cancer cell separation in fresh whole blood. Biomaterials. 2011;32(36):9758-65.

59. Prince MR, Zhang HL, Chabra SG, Jacobs P, Wang Y. A pilot investigation of new superparamagnetic iron oxide (ferumoxytol) as a contrast agent for cardiovascular MRI. J X-ray Sci Technol. 2003;11(4):231-40.

60. Bashir MR, Bhatti L, Marin D, Nelson RC. Emerging applications for ferumoxytol as a contrast agent in MRI. J Magn Reson Imaging. 2014.

61. Bullivant JP, Zhao S, Willenberg BJ, Kozissnik B, Batich CD, Dobson J. Materials characterization of feraheme/ferumoxytol and preliminary evaluation of its potential for magnetic fluid hyperthermia. Int J Mol Sci. 2013;14(9):17501-10.

62. Feraheme. Highlights of prescribing information 2013. Available from: http://www.feraheme.com/pdfs/ Feraheme_Prescribing_Information.pdf. Accessed 1 Mar 2015

63. Burns DL, Pomposelli JJ. Toxicity of parenteral iron dextran therapy. Kidney Int Suppl. 1999;69:S119-24.

64. Vychytil A, Haag-Weber M. Iron status and iron supplementation in peritoneal dialysis patients. Kidney Int Suppl. 1999;69:S71-8.

65. Fishbane S, Ungureanu VD, Maesaka JK, Kaupke CJ, Lim V, Wish J. The safety of intravenous iron dextran in hemodialysis patients. Am J Kidney Dis. 1996;28(4):529-34.

66. Landry R, Jacobs PM, Davis R, Shenouda M, Bolton WK. Pharmacokinetic study of ferumoxytol: a new iron replacement therapy in normal subjects and hemodialysis patients. Am J Nephrol. 2004;25(4):400-10.

67. Spinowitz BS, Schwenk MH, Jacobs PM, Bolton WK, Kaplan MR, Charytan C, et al. The safety and efficacy of ferumoxytol therapy in anemic chronic kidney disease patients. Kidney Int. 2005;68(4):1801-7.
68. Spinowitz BS, Kausz AT, Baptista J, Noble SD, Sothinathan $\mathrm{R}$, Bernardo MV, et al. Ferumoxytol for treating iron deficiency anemia in CKD. J Am Soc Nephrol. 2008;19(8):1599-605.

69. Dosa E, Guillaume DJ, Haluska M, Lacy CA, Hamilton BE, Njus JM, et al. Magnetic resonance imaging of intracranial tumors: intra-patient comparison of gadoteridol and ferumoxytol. Neuro-Oncology. 2011;13(2):251-60.

70. Nainani N, Panesar M. Nephrogenic systemic fibrosis. Am J Nephrol. 2008;29(1):1-9.

71. Gaglia JL, Harisinghani M, Aganj I, Wojtkiewicz GR, Hedgire $\mathrm{S}$, Benoist $\mathrm{C}$, et al. Noninvasive mapping of pancreatic inflammation in recent-onset type- 1 diabetes patients. Proc Natl Acad Sci. 2015;112(7):2139-44.

72. Thorek DL, Ulmert D, Diop N-FM, Lupu ME, Doran MG, Huang R, et al. Non-invasive mapping of deep-tissue lymph nodes in live animals using a multimodal PET/MRI nanoparticle. Nat Commun. 2014;5.

73. Thu MS, Bryant LH, Coppola T, Jordan EK, Budde MD, Lewis $\mathrm{BK}$, et al. Self-assembling nanocomplexes by combining ferumoxytol, heparin and protamine for cell tracking by magnetic resonance imaging. Nat Med. 2012;18(3):463-7.

74. Kaittanis C, Shaffer TM, Ogirala A, Santra S, Perez JM, Chiosis $\mathrm{G}$, et al. Environment-responsive nanophores for therapy and treatment monitoring via molecular MRI quenching. Nat Commun. 2014;5:3384.

75. Slowing II, Trewyn BG, Giri S, Lin VY. Mesoporous silica nanoparticles for drug delivery and biosensing applications. Adv Funct Mater. 2007;17(8):1225-36.

76. Qhobosheane M, Santra S, Zhang P, Tan W. Biochemically functionalized silica nanoparticles. Analyst. 2001;126(8):1274-8.

77. Albanese A, Tang PS, Chan WC. The effect of nanoparticle size, shape, and surface chemistry on biological systems. Annu Rev Biomed Eng. 2012;14:1-16.

78. Gref R, Minamitake Y, Peracchia MT, Trubetskoy V, Torchilin $\mathrm{V}$, Langer R. Biodegradable long-circulating polymeric nanospheres. Science. 1994;263(5153):1600-3.

79. Kolhar P, Anselmo AC, Gupta V, Pant K, Prabhakarpandian B, Ruoslahti E, et al. Using shape effects to target antibody-coated nanoparticles to lung and brain endothelium. Proc Natl Acad Sci. 2013;110(26):10753-8.

80. Klose D, Siepmann F, Elkharraz K, Krenzlin S, Siepmann J. How porosity and size affect the drug release mechanisms from PLGA-based microparticles. Int J Pharm. 2006;314(2):198-206.

81. Chithrani BD, Ghazani AA, Chan WC. Determining the size and shape dependence of gold nanoparticle uptake into mammalian cells. Nano Lett. 2006;6(4):662-8.

82. Champion JA, Mitragotri S. Role of target geometry in phagocytosis. Proc Natl Acad Sci U S A. 2006;103(13):4930-4.

83. Slowing II, Vivero-Escoto JL, Wu C-W, Lin VS-Y. Mesoporous silica nanoparticles as controlled release drug delivery and gene transfection carriers. Adv Drug Deliv Rev. 2008;60(11):127888.

84. Stöber W, Fink A, Bohn E. Controlled growth of monodisperse silica spheres in the micron size range. J Colloid Interface Sci. 1968;26(1):62-9.

85. Kresge C, Leonowicz M, Roth W, Vartuli J, Beck J. Ordered mesoporous molecular sieves synthesized by a liquid-crystal template mechanism. Nature. 1992;359(6397):710-2.

86. Barbe C, Bartlett J, Kong L, Finnie K, Lin HQ, Larkin M, et al. Silica particles: a novel drug-delivery system. Adv Mater. 2004;16(21):1959-66.

87. Chen Y, Chen H, Ma M, Chen F, Guo L, Zhang L, et al. Double mesoporous silica shelled spherical/ellipsoidal nanostructures: synthesis and hydrophilic/hydrophobic anticancer drug delivery. J Mater Chem. 2011;21(14):5290-8.

88. Lu J, Liong M, Zink JI, Tamanoi F. Mesoporous silica nanoparticles as a delivery system for hydrophobic anticancer drugs. Small. 2007;3(8):1341-6.

89. Phillips E, Penate-Medina O, Zanzonico PB, Carvajal RD, Mohan $\mathrm{P}, \mathrm{Ye} \mathrm{Y}$, et al. Clinical translation of an ultrasmall inorganic optical-PET imaging nanoparticle probe. Sci Transl Med. 2014;6(260):260ra149.

90. Radu DR, Lai C-Y, Jeftinija K, Rowe EW, Jeftinija S, Lin VS-Y. A polyamidoamine dendrimer-capped mesoporous silica 
nanosphere-based gene transfection reagent. J Am Chem Soc. 2004;126(41):13216-7.

91. Giri S, Trewyn BG, Stellmaker MP, Lin VSY. Stimuli-responsive controlled-release delivery system based on mesoporous silica nanorods capped with magnetic nanoparticles. Angew Chem Int Ed. 2005;44(32):5038-44.

92. Ow H, Larson DR, Srivastava M, Baird BA, Webb WW, Wiesner U. Bright and stable core-shell fluorescent silica nanoparticles. Nano Lett. 2005;5(1):113-7.

93. Burns AA, Vider J, Ow H, Herz E, Penate-Medina O, Baumgart $\mathrm{M}$, et al. Fluorescent silica nanoparticles with efficient urinary excretion for nanomedicine. Nano Lett. 2009;9(1):442-8.

94. Benezra M, Penate-Medina O, Zanzonico PB, Schaer D, Ow H, Burns A, et al. Multimodal silica nanoparticles are effective cancer-targeted probes in a model of human melanoma. J Clin Invest. 2011;121(7):2768-80.

95. Bradbury MS, Phillips E, Montero PH, Cheal SM, Stambuk H, Durack JC, et al. Clinically-translated silica nanoparticles as dual-modality cancer-targeted probes for image-guided surgery and interventions. Integr Biol. 2013;5(1):74-86.

96. Peng G, Tisch U, Adams O, Hakim M, Shehada N, Broza YY, et al. Diagnosing lung cancer in exhaled breath using gold nanoparticles. Nat Nanotechnol. 2009;4(10):669-73.

97. Xu ZQ, Broza YY, Ionsecu R, Tisch U, Ding L, Liu H, et al. A nanomaterial-based breath test for distinguishing gastric cancer from benign gastric conditions. Br J Cancer. 2013;108(4):94150 .

98. Maggiorella L, Barouch G, Devaux C, Pottier A, Deutsch E, Bourhis $\mathrm{J}$, et al. Nanoscale radiotherapy with hafnium oxide nanoparticles. Future Oncol. 2012;8(9):1167-81.

99. Michalet X, Pinaud FF, Bentolila LA, Tsay JM, Doose S, Li JJ, et al. Quantum dots for live cells, in vivo imaging, and diagnostics. Science. 2005;307(5709):538-44.

100. Tsoi KM, Dai Q, Alman BA, Chan WC. Are quantum dots toxic? Exploring the discrepancy between cell culture and animal studies. Acc Chem Res. 2012;46(3):662-71. 